\title{
Research on Establishment of Procuratorial Supervision Organization under Judicial Reform
}

\author{
Zixin Wang \\ School of Law \\ Wuhan University of Technology \\ Wuhan City, China \\ 944916842@qq.com
}

\begin{abstract}
As an organ of legal supervision set up according to the Constitution of China, the People's Procuratorate does not completely make people satisfy its supervision in practice. The reasons are from two aspects; one is that the definition of procuratorial supervision is not clear; the other is that mechanism for procuratorial supervision is not advanced in establishment. The paper focuses on solving the two issues. Making sense of the connotation of procuratorial supervision paves a road for theoretical analysis and mechanism establishment. Insisting proper separation of litigation function from supervision function is an effective way to intensify the function of procuratorial supervision. Setup of split mode and special mode is an effective attempt of such reform.
\end{abstract}

Keywords-Procuratorial supervision; Split mode; Special mode; Professionalized authority

There is a definite stipulation in the Constitution that the people's Procuratorate is an organ of legal supervision in China, which means legal oversight is a basic function for procuratorial organ. The past implementation of supervision right of procuratorial organization focused on fighting against the duty-related crimes of people working in nationwide organs and of national staff through litigious activities. But the functions of procuratorial organizations were carried out new adjustment and division with the reform of judicial system and procuratorial system. The overall affiliation transfer of Anti-corruption \& bribery Bureau and Anti-infringement Bureau made the procuratorate's mode of executing supervision experience a deep change. Under the background of new judicial system's reform, to further classify the connotation of procuratorial supervision and set up scientific procedures for its fulfillment became a hotspot of research and discussion in the judicial field once more.

\section{CONCEPTUAL CATEgORY OF PROCURATORIAL SUPERVISION}

\section{A. Background of concept repeating of procuratorial} supervision

With the profound development of judicial reform, the connotation of procuratorial supervision also has been expanding. The third plenary session of the $18^{\text {th }}$ National Congress of CPC put forward a requirement to further perfect the linkage between administrative law enforcement and criminal division, so as to make procuratorial supervision extend to the field of administrative law enforcement. The forth plenary session of the $18^{\text {th }}$ National Congress of CPC also came up with the strategic requirement "to enhance the legal system for organs of supervision in execution of supervision rights. Since last year, the working environment, goal, task and the like of procuratorial organs had occurred a significant change with the constant development of the two reforms. The traditional function allocation and working mode can't adapt the development of new trend any more. Therefore, to intensify the function of legal oversight of procuratorial organs has become a consensus in judicial circle. On July 20, 2016, CAO Jianming, the Chief Procurator, stressed at the $14^{\text {th }}$ national procuratorial work meeting that procuratorial organizations at all levels should take deepening of judicial system reform as the key matter to perfect procuratorial supervision system and increase procuratorial supervision capability. Accordingly, it is an unavoidable route for procuratorial organizations under the big trend of reform to value the constitutional position of legal supervision more greatly, to constantly improve procuratorial supervision system and to thoroughly strengthen procuratorial supervision.

\section{B. Concept definition of procuratorial supervision}

There are a few stipulations on procuratorial supervision in Chinese legal system, and these stipulations are relatively unspecific, which contributes to the disagreement on defining the concept and category of procuratorial supervision has existed between theoretical circle and practical circle. There are two mainstream opinions. One thinks the category of procuratorial supervision should not be limited to litigious supervision. This view is a general understanding to supervision right of procuratorial organizations, which lists the functional rights performed by procuratorial organs to participate in the comprehensive governance of society and prevention of criminal commitment and so forth beyond litigious oversight into the category of supervision function[1]. The other is more direct, believes the supervision of procuratorial organs consists of investigation supervision, adjudication supervision, criminal execution supervision, civil lawsuit supervision and administrative lawsuit supervision. The later thinks procuratorial supervision is equal to litigious supervision and it is extensively accepted in practice.

In the author's opinion, procuratorial supervision is an umbrella name of all legal supervision functions that the People's Procuratorate fulfills according to the Constitution and laws. Specifically, it refers to litigious supervision and oversight of administrative right. While the above said public 
interest litigation system is included in the supervision function of procuratorial organs to administrative right [2]. In concept, procuratorial supervision is the subordination concept of legal oversight and also is the superordination concept of litigious supervision[3]. Procuratorial supervision is not equivalent to litigious supervision. It is not only the development of litigious supervision, but also the surpassing of litigious supervision. Based on that, the view that considers the both same obviously mixes the relationship between the both, and shortens the connotation of procuratorial supervision. Strengthening legal supervision to lawsuit activities, perfecting judicial supervision to administrative mandatory measures, supervising administrative unlawful behaviors and establishing dominant position for public interest litigation can make extension of procuratorial supervision specific and clear, and also can make procuratorial supervision exceed the category of traditional civil procuratorate and administrative procuratorate and develop up to the strategic height of national governance system and governance ability modernization.

\section{SituAtion AND PRoblems of Procuratorial SUPERVISION}

The procuratorial organization taking litigious function and supervision function concurrently is a significant presentation of the procuratorial system with Chinese characteristics. Traditionally, the fulfillment of Chinese procuratorial supervision function is carried out alternatively together with litigious function all the time, and supervision function is reported to litigious authority for treatment. As for setting, the majority of procuratorial organs adopt power configuration mode and set up built-in institutions for different phases of litigation in accordance with the setting standard of the functional organizations of the Supreme People's Procuratorate, and emerge the supervision and lawsuit departments and then establish them, to let participants of lawsuit activities directly perform procuratorial supervision function and develop litigious oversight by promotion of litigious activities. In the long run, the procuratorial situation in which litigious function and supervision function mix mutually stepwise came into being. Namely, the aforesaid issue of litigation tendency of procuratorial supervision. Specifically, the issues contributed to by such mode include the following dimensions. First, from external supervision, there are patterns in which procuratorial organs, investigation organs and adjudication organs mutually supervise and limit in litigious activities. Such patterns will affect and restrict the fulfillment of procuratorial supervision right at the time of merger and establishment of institutions. Second, if there are merger and establishment of institutions, heavy workload, insufficient supervision resources and lack of personnel energy, it is more likely to occur an unbalanced condition that procuratorial personnel inclines to deal with the "hard task" of lawsuit and ignore the "soft task" of supervision. Ultimately, lawsuit function and supervision function operate in different laws, and lawsuit maker and supervisor have conflicts and contradictions in their roles. Essentially, supervision right is a right of procedure starting, supervisors will start or terminate one particular procedure when performing supervision; while litigious right requires more of participating and personal experience, and it is interfered in and handled by lawsuit makers proactively.

\section{NEW ChANGES OF PROCURATORIAL SUPERVISION AFTER JUDICIAL REFORM}

After judicial reform, procuratorial organs stepwise take measures to intensify supervision, to strengthen procuratorate's oversight function and deal with the issues arising from uniform performance of litigation function and oversight function. Every local place formed some new modes in reform practice and obtained valuable experience and considerable achievements.

\section{A. New modes of procuratorial supervision}

New procuratorial supervision modes of China vary with the judicial practices of each area. Among them, there are two typical modes. One is the special mode of Hubei Province---setting up litigation and supervision departments uniformly, and the other is split mode of Beijing City---setting up the supervision departments for different functions respectively.

\section{B. Advantages of procuratorial supervision right under new modes}

The existing data shows that the quantity and quality of supervision cases and executive efficiency of oversight all have had a dramatic improvement after the supervisory organizations were split. The following are the specific advantages:

First, Supervision is intensified. Separation of supervision function from litigation institution makes supervision function free from restriction of litigation function and makes its independent execution possible. Additionally, it also can resolve long-term litigious inclination of procuratorial supervision more completely. Establishing a special supervisory body and allocating supervision personnel make the supervision function become a job as important as litigation function, so the issue of favoring litigation more than supervision will not happen any longer.

Second, oversight is specified. The split mode specifies every supervisory body's investigation right for cases and confirms contents of litigation and supervision[4]. Scientific function division, optimization of resource integration and compliance with supervision law are carried out pursuant to different functional properties and operational laws, which make procuratorial staff, get away from paradoxical role dilemma, and causes oversight to be performed more smoothly.

Third, professionalized level of supervision is enhanced. Special department for supervision is set up according to different links and functions. Special staff is designated to fulfill supervision function and handle related cases. Those make labor division much clearer, make procedures more specific and work efficiency much higher. Furthermore, specialized transaction of supervisory cases makes supervisory resources and force more intensive.

Forth, procuratorial power is standardized. The relationship between litigation and supervision department and litigation function department is mutual oversight. It favors to strengthen internal oversight of procuratorial organ itself. Letting different organizations respectively carry out litigation function and supervision function is helpful to supervise, restrain and 
prevent abuse and misuse of power and casualness of law enforcement, so as to force procuratorial officers to practically deal with cases and judicial justice.

All in all, splitting establishment of supervisory body can facilitate moderate separation of litigation and supervision functions. In the meanwhile, their moderate split makes labor division and cooperation between them more scientific. And both each performing its own function and mutual coordination become possible, which is like wings of a bird and double wheels of a vehicle, they are indispensable[5].

\section{CONCLUSION}

Whatever the requirement of policy or trend, to intensify procuratorial supervision is an indispensable trend for procuratorial organs to experience in development. Maintaining moderate split of litigation function and supervision function is a good remedy to strengthen supervision function. Smooth operation of new modes also can provide further judicial reform with a good example. Mode of splitting supervisory department has produced good efficiency in practice, which can enhance supervision force and effectively increase fulfillment and efficiency of supervision function. A department integrating litigation and supervision concurrently is suitable for a small-sized procuratorate. It not only can intensively fulfill oversight but also save force resources, and avoid unnecessary internal friction and prevent overstaffed and cumbersome situation from happening to departments.

\section{REFERENCES}

[1] DENG Jihao. Considering the Split of Litigation Power and Supervision Power from Two Properties of Procuratorial Supervision, reprint Politics and Laws, the 3rd issue of 2012.

[2] JING Dali. Complete Implementation of Spirit of the Centre, Intensification of Procuratorial Supervision of New Period, reprint Procuratorial Daily, January 18, 2017.

[3] JING Dali. Improvement of Institutionalization Level of Procuratorial Supervision, reprint The People's Procuratorial Supervision, the 23rd issue of 2016.

[4] Subject group of the People's Procuratorate, Shijingshan District, Beijing City: Basic Issues on Optimal Allocation of Litigious and Supervisory Power, reprint Research on Deepening Basic Theory Issues of Procuratorial Reform-Collected Works of the 2nd Basic Procuratorial Theory Forum of China.

[5] Procuratorial Development and Research Center in Hubei Province: Implementation of "Two Moderate Separations for Optimizing Allocation of Procuratorial Function, reprint The People's Procuratorial Supervision, the 24th issue of 2010. 